\title{
The pathology of mesotheliomata and an analysis of their association with asbestos exposure
}

\author{
DERMOT O'B. HOUR I H A N E \\ From the Department of Pathology, The London Hospital Medical School, and The Bernhard Baron \\ Institute of Pathology
}

Primary tumours of serosal membranes are uncommon and their diagnosis is difficult. Several authorities deny that they are more than rare curiosities (Willis, 1960 ; Smart and Hinson, 1957). The pathology of pleural tumours was defined by Klemperer and Rabin (1931), and their general division into localized (usually fibrous) and diffuse (usually epithelial) tumours still obtains. Since Godwin (1957) laid down strict criteria for pleural tumours and Winslow and Taylor (1960) for peritoneal, the diagnosis of these neoplasms has become more common (McCaughey, 1958 ; Manguikian and Prior, 1963). The association between pleural tumours and exposure to asbestos was first noted by Wagner (1960) in South Africa, and this work has been extended subsequently (Wagner, Sleggs, and Marchand, 1960).

The present report concerns a review of all the cases recorded as primary diffuse tumours of the pleura or peritoneum (mesotheliomata) in the necropsy files of the Bernhard Baron Institute of Pathology at The London Hospital. The dates covered by this review were from 1917 to 1962 inclusive. In all cases necropsy protocols and histological slides were available for study.

Strict criteria are essential in the diagnosis of these tumours, and the first of these is that a full necropsy examination should fail to find a primary tumour within the viscera. Suspicious lesions, such as bronchial thickening or stenosis, or gastric ulcers, must be histologically examined before primary carcinoma of these sites can be excluded. In the absence of histological examination of such lesions, the case cannot be accepted as a primary tumour of serosal membrane.

In addition, the morbid anatomy of mesothelioma must be fulfilled, that is, tumour spread throughout the pleura or peritoneum as a diffuse sheet of white or grey-yellow firm tissue, or discrete and confluent nodular plaques. The tumour is usually rubbery firm in consistency but may have soft gelatinous foci within it. Tumour is commonly present in more than one serosal cavity, and effusions, sometimes mucoid, are often associated.

Underlying viscera are rarely invaded to any depth, so that in the gut, for example, it is most unusual for the tumour to extend through the muscularis propria. Both the serosal surface and the outer millimetre or two of muscle are commonly involved. Lymph node metastases are common, but parenchymal metastases in the viscera are rare. When such parenchymal lesions are present it has been found that the viscus has usually been surrounded by tumour, and I have accepted a small number of cases with such parenchymal lesions as mesotheliomata, since retrograde lymphatic permeation was thought to be a more plausible mechanism of spread than haematogenous dissemination. In no instance were parenchymal lesions widespread, and usually they were represented by solitary lesions in the adrenal, pancreas, or liver.

Metastases in bone were never found within the right femur, which had been examined in all cases, and were restricted to the vertebral bodies and ribs. It was felt that direct invasion of bone was the most likely mechanism of spread to these sites. In no case were bony lesions found which were not in continuity with the serosal tumour.

In addition to its morbid anatomy, the tumour must show a typical histological appearance. The commonest type described in previous reports and usually associated with diffuse spread through the serosal cavity is the 'epithelial' form. In this, the pattern is that of large tubules, often loosely formed, and with a sinuous or scalloped outline (Fig. 1). Epithelial folds of lining cells or true papillae with hyaline connective tissue stalks are commonly seen projecting into the tubule, and occasionally the tubule is filled with cells. The lining elsewhere is of a single layer of cells, often detached from neighbouring cells and with occasional single cells lying loose in the lumen. The second pattern, also of epithelial type, is that of solid groups of cells without clear tubule forma- 


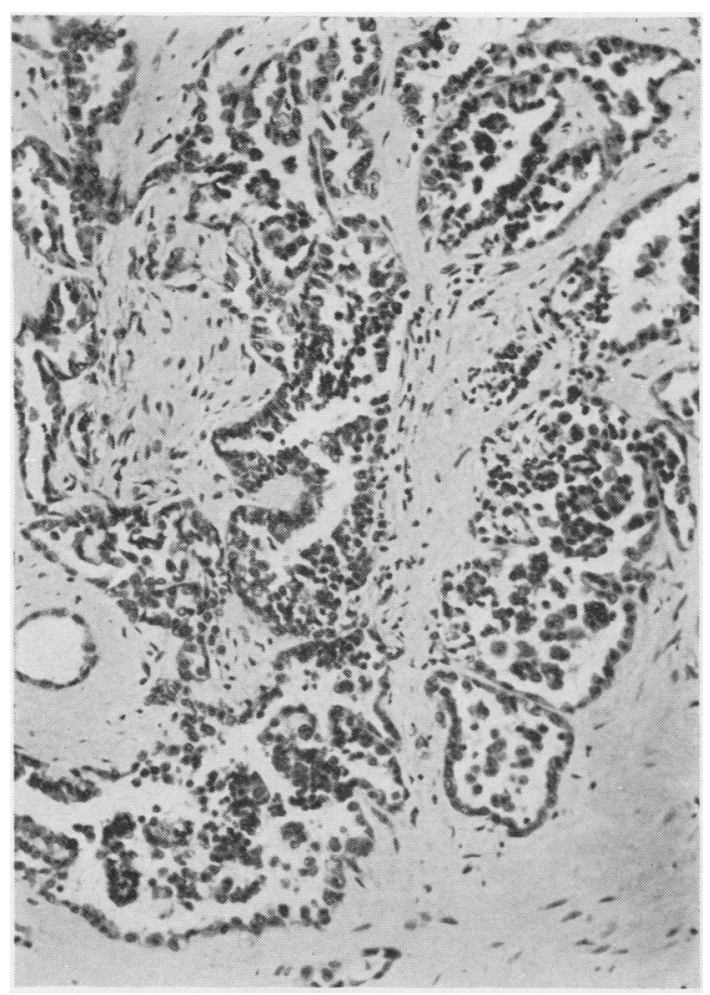

FIG. 1

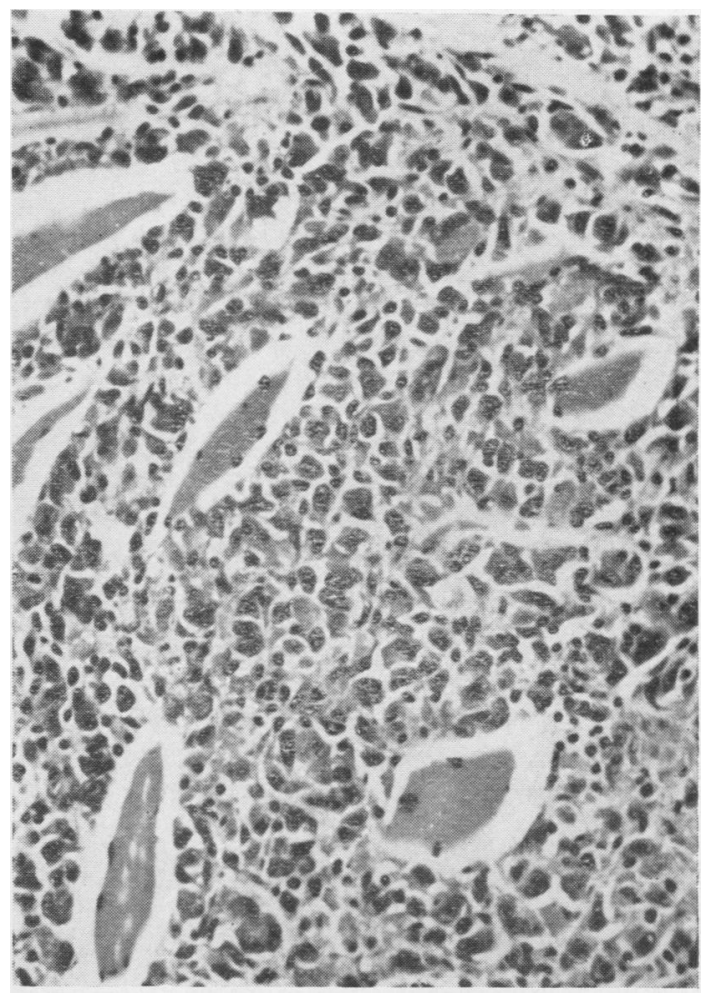

FIG. 2

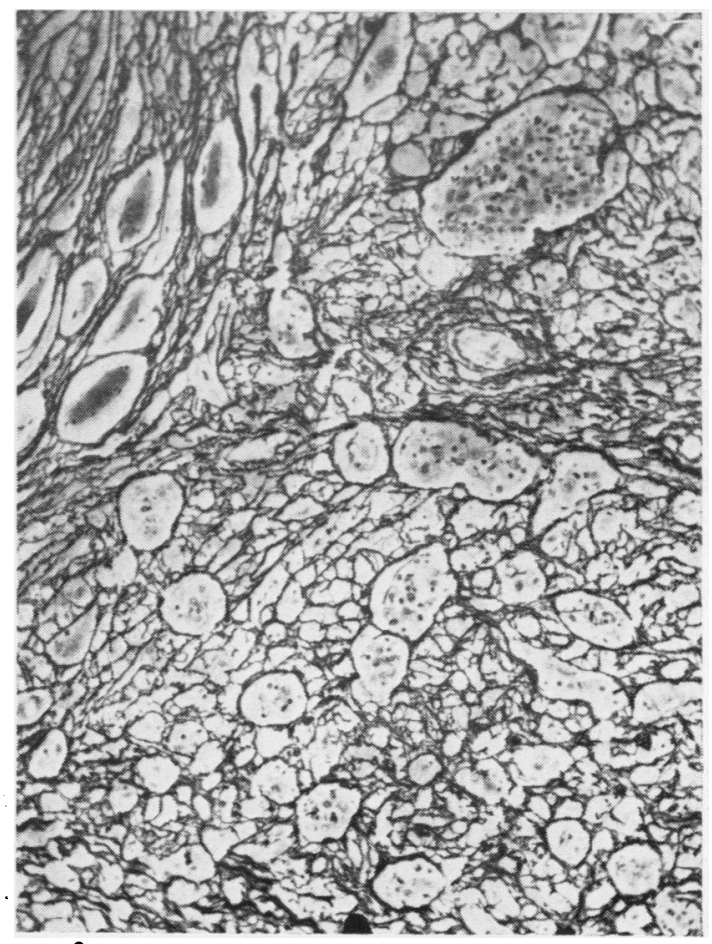

FIG. 3
FIG. 1. Case 2. Typical epitheliai type of mesothelioma. Shows loosely-formed tubules with irregular outer borders. The tubules are lined by a single layer of cells, with numerous epithelial folds and papiliae; when these are not sectioned through their stalks, the appearance of cells lying free in lumina is given. Haematoxylin and eosin, $\times 130$.

FIG. 2. Case 17. Solid epithelial-type tumour invading between voluntary muscle fibres of intercostal muscle. Haematoxylin and eosin, $\times 220$.

FIG. 3. Case 17. Same area as in Fig. 2. Reticulin fiores arranged around groups of tumour cells, and, in centre of field, around single cells. Voluntary muscle fibres in top left corner. Gomori's reticulin preparation, $\times 120$. 
tion, but in these the reticulin fibres show an alveolar or trabecular pattern not detectable with haematoxylin and eosin (Figs. 2 and 3).

In these types of tumour, the stroma between the groups of cells is unremarkable; it may be hyaline but is more commonly composed of cellular connective tissue with small inconspicuous fibroblasts (fibrocytes). Cytologically, it does not appear to be neoplastic and is similar to the connective tissue of any carcinoma.

The malignant mesothelial cell of epithelial type is large and polygonal, with amphophilic cytoplasm - occasionally eosinophilic - with clear cytoplasmic membranes. The nucleus is round, occupies about one-third of the cell, and shows a loose vesicular arrangement of chromatin. The nuclear membrane may be folded or crenated, and a large, round eosinophilic nucleolus is a very common feature (Fig. 4); multiple nucleoli may be found. Small intracytoplasmic vacuoles are focally present in many lesions, and occasionally a single

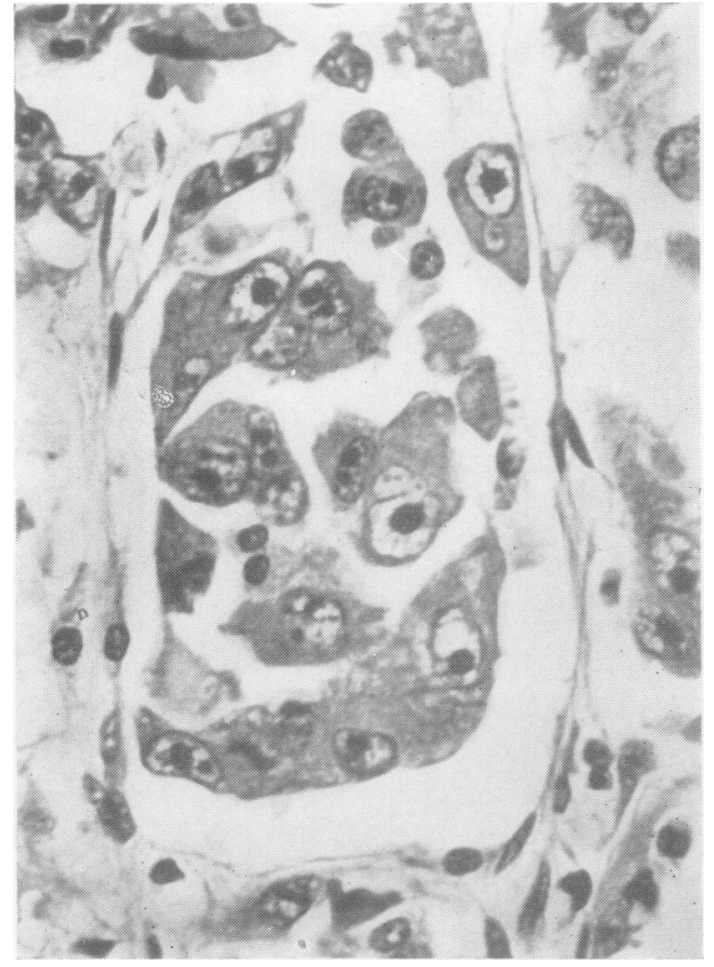

FI.G 4. Case 17. Loosely-formed group of tumour cells in the pleura. Cells are large, with abundant amphophilic cytoplasm. Nuclei show prominent cosinophilic nucleoli, and the central cell shows a folded nuclear membrane. Haematoxylin and eosin, $\times 600$.

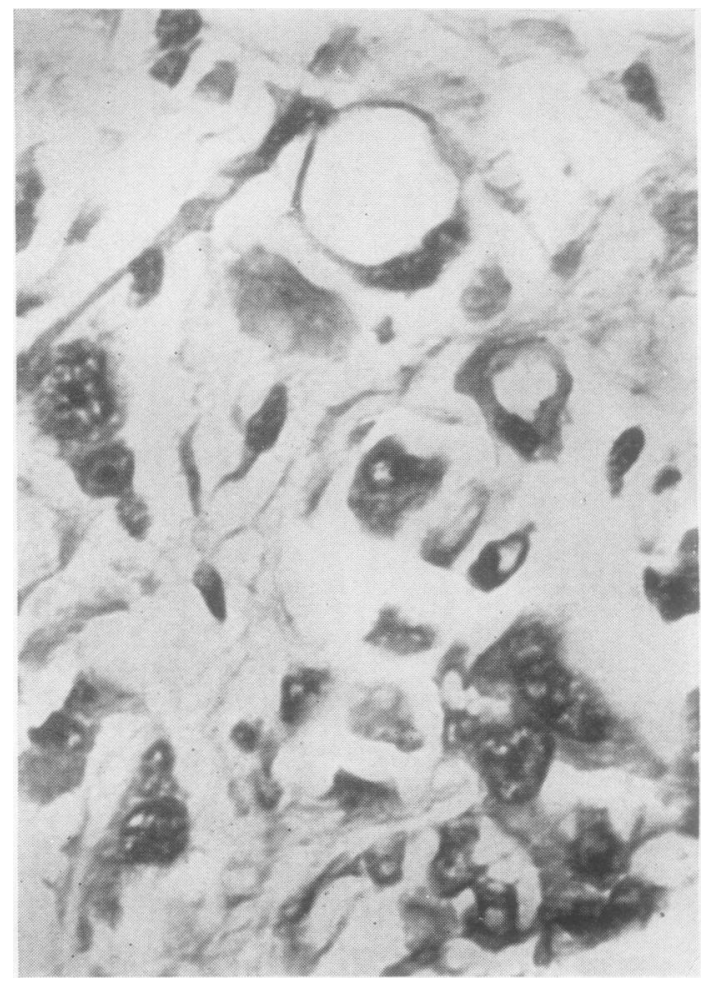

FIG. 5. Case 13. Epithelial-typo area in pleural tumour. Large cytoplasmic vacuoles have displaced the nuclei eccentrically. The peripheral rims of the vacuoles stain metachromatically (violet) with thionin. Haematoxylin and cosin, $\times 750$.

large vacuole appears to distend the cell and displace the nuclei to an eccentric peripheral position so that the cells look like fat cells (Fig. 5). These vacuoles do not stain as epithelial mucin with periodic acid Schiff or muci-carmine but may react metachromatically with various stains (see later). Widespread massive necrosis is uncommon, but small microscopic foci of eosinophilic necrosis are quite frequent. Mitoses are rarely found, but double-nucleated and even multinucleated tumour cells are not uncommon. The cells may vary to some degree in size, but the general appearances are those of even regularity. Even the largest cells have the same characteristics as those already described, and pleomorphism (in so far as variation in staining and shape is concerned) is absent.

Psammoma bodies, stromal calcification or ossification within the tumour were never seen. Lymphatic permeation was observed in a few cases. 


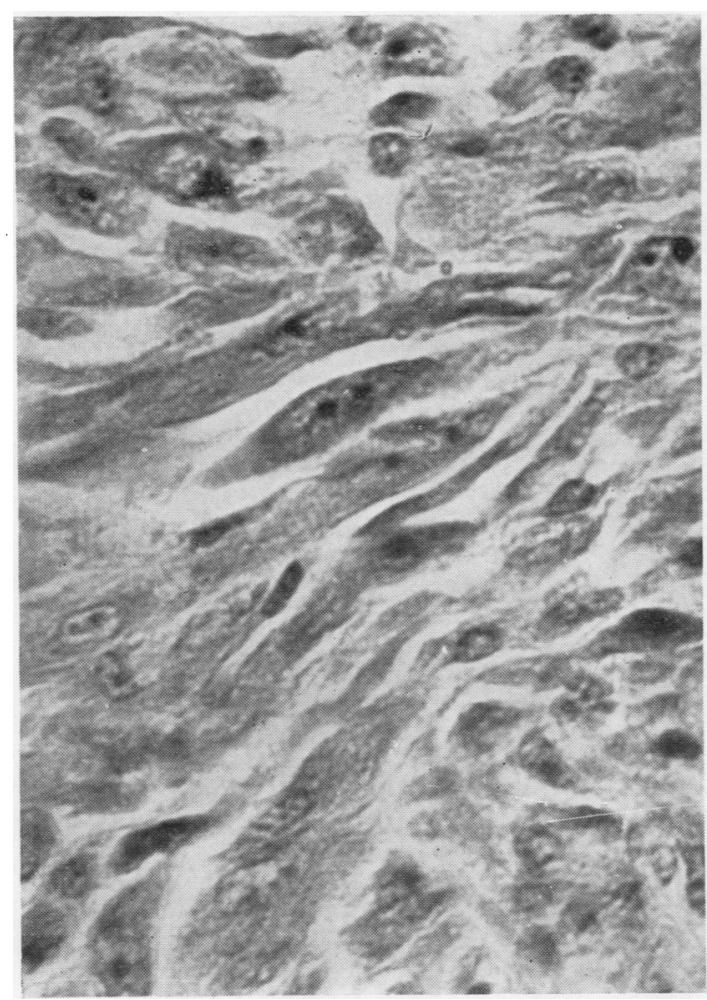

FIG. 6. Case 10. Pleural tumour. The central cells are spindle-shaped but still show vesicular nuclei and eosinophilic nucleoli. Haematcxylin and eosin, $\times 750$.

The cells of the 'fibrous' types are spindleshaped with oval nuclei arranged with longitudinal axes parallel to those of the cells. The oval nuclei are often vesicular, and prominent eosinophilic nucleoli are common (Fig. 6). The cells are also in parallel, loosely arranged in indistinct fascicles that gently fuse into each other, unlike the angled intersections of the leiomyosarcoma or fibrosarcoma. On transverse sections the fascicles are often clearly rounded and slightly whorled. Occasionally the cells are arranged parallel to the surface of the underlying viscus with little or no fasciculation.

Reticulin fibres surround these cells in a closely woven meshwork of thin strands, and occasionally the fibres are thick, dense, and brown. The latter are found in acellular, hyaline areas, which are common in these tumours. Mitoses are uncommon, but a few tumours show areas of pleomorphism with tumour giant cells and frequent mitoses. Figure 7 shows the histology of a fibromatous tumour with abundant collagen formation.
Tumours of this fibromatous type were described by Klemperer and Rabin (1931) as forming a localized mass in the serosal space, but all my cases showed diffuse involvement of the pleura or peritoneum. One case showed a large mass in addition to diffuse involvement of the pleura.

Both epithelial and fibromatous elements were found in $41 \%$ (14 cases), and both types might be found in the same microscopical field (Fig. 12) in the same anatomical area or in different sites of tumour (Figs. 8 and 9). All lesions in bone (direct invasion of vertebrae or ribs) were fibromatous in type (Fig. 8), often with epithelial type in all other lesions. Metastases in lymph nodes were usually of epithelial type irrespective of the type of the primary tumour (Fig. 9). It is possible that the structure of the organ may affect the histological appearances of the tumour.

In contrast to mesothelioma, when a carcinomatous metastasis is present in bone, it is frequently 'scirrhous', that is it shows a fibrous

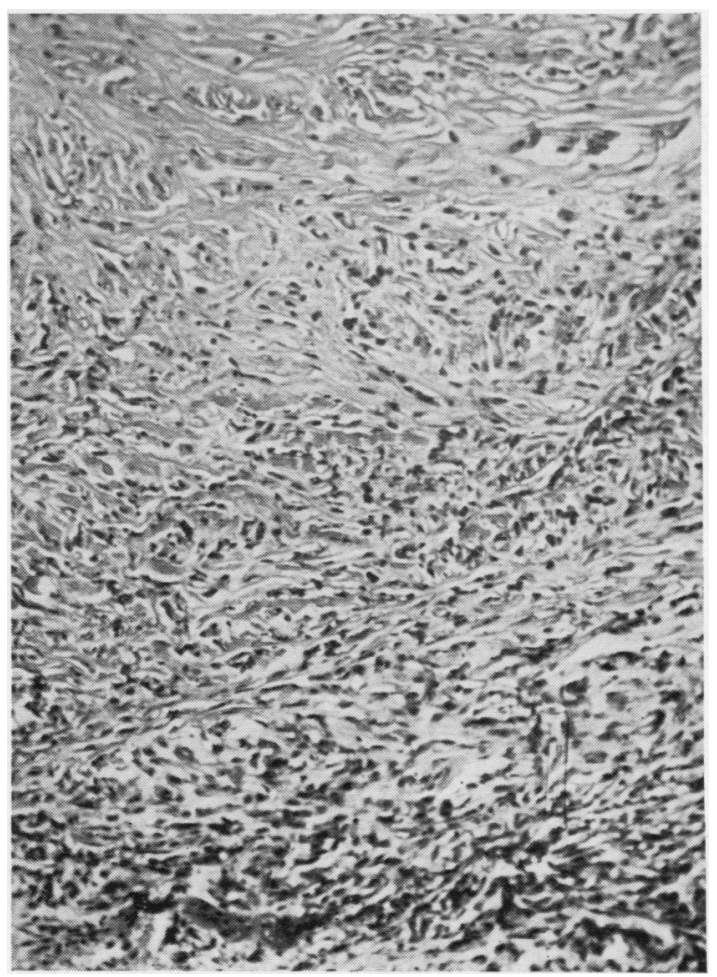

FIG. 7. Case 5. Fibromatous pleural tumour. Collagenous tissue at top of photograph. Inflammatory cells at bottom. The similarity of this area to benign pleural thickening (Fig. 11) is striking. Haematoxylin and eosin, $\times 110$. 


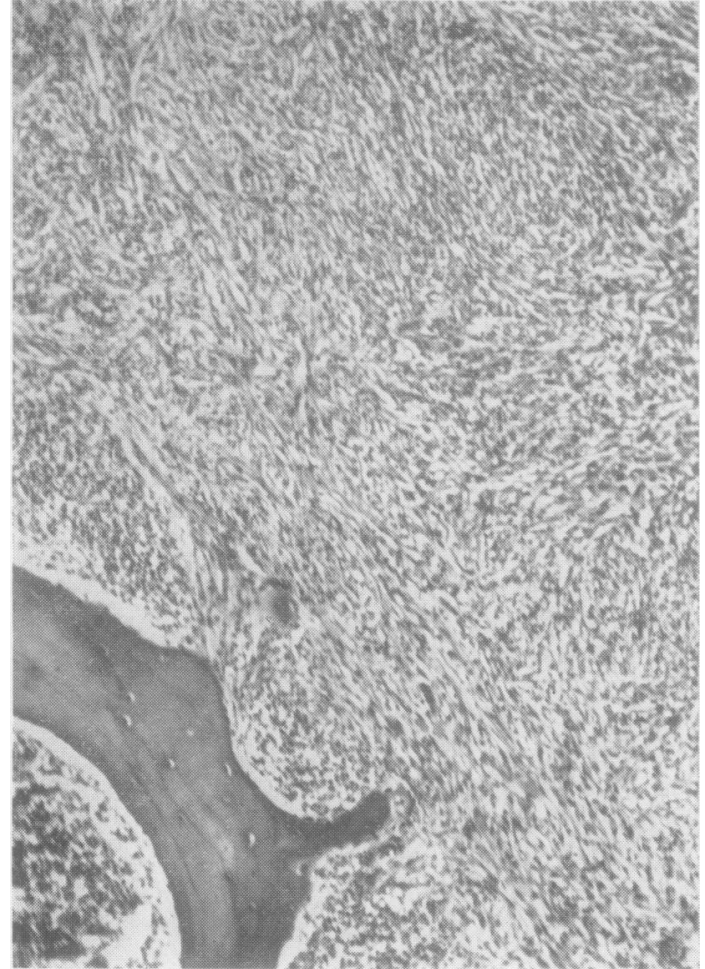

FIG. 8

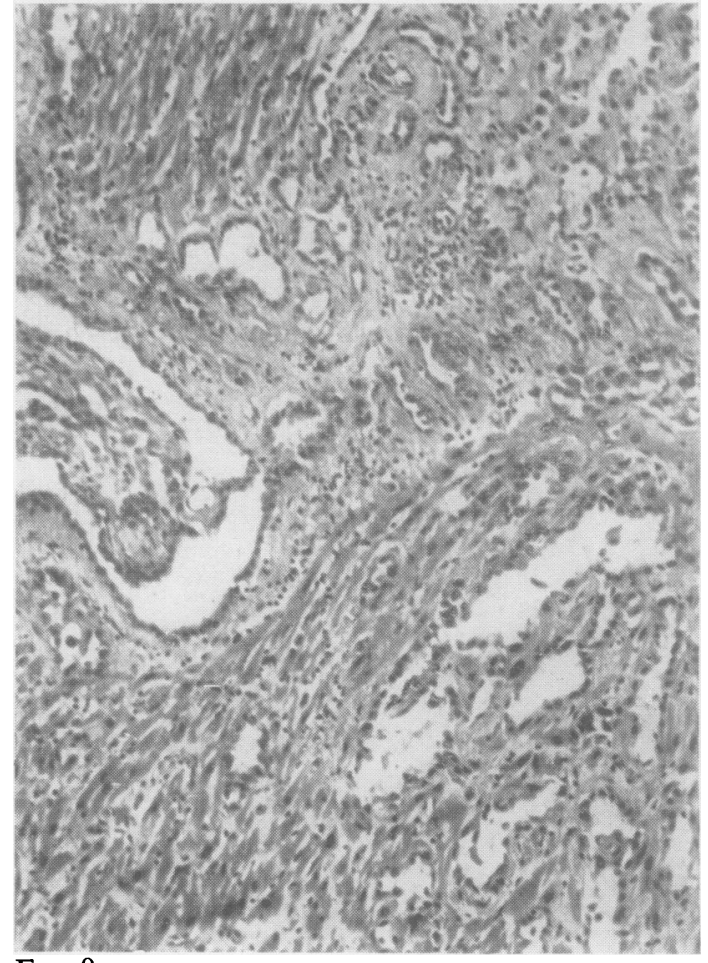

FIG. 9

FIG. 8. Case 28. Fibromatous tumour in vertebral body. Haematoxylin and eosin, $\times 80$.

FIG. 9. Same case as in Fig. 8. Epithelial-type tumour involving pericardium and shoun here invading myocardium. Haematoxylin and eosin, $\times 110$.

stroma which may be the predominant feature. However, epithelial elements are always focally present, and the entire lesion is not composed of spindle-shaped cells without epithelial arrangement.

In the group of pleural tumours, blocks of lung parenchyma were available in all. In the peritoneal group, blocks of lung were available in 16 cases. Asbestos bodies were looked for with haematoxylin and eosin stains, and no additional stains were required. In most of the cases, one block only of the lung was available, and no tissue could be obtained for further study. The incidence of asbestos bodies was consequently the lowest possible and would probably have been much higher if they had been looked for at the time of necropsy, or if multiple blocks of lung had been taken from the lungs.

In a few cases, brown, homogeneous, round bodies, which could not be identified, were found in the lungs. These have been recorded as queries, and have been counted as negative findings in calculations of the incidence of exposure to asbestos. Only those brown bodies with classically described features of asbestos bodies have been accepted as such. A case was recorded as asbestosis if fibrosis of the lung was present in addition to asbestos bodies and fibres. The fibrosis was usually peribronchial or interstitial.

Thirty-eight tumours were filed as primary pleural mesotheliomata. On review of each case, 21 cases were rejected from this series. Many of $\omega$ these were adenocarcinomata or oat-cell carcinomata of the lung, with predominant spread to pleural membranes. Widespread visceral metastases were usually present.

Seventeen cases were accepted. These have been divided into two groups: (A) Cases in which the morbid anatomy and histology were exactly typical of mesotheliomata (certain cases); (B) cases in which the morbid anatomy or histology showed features not typical, e.g., foci of pleo- 
TABLE I

\begin{tabular}{|c|c|c|c|c|c|c|c|c|c|c|c|c|c|c|c|c|}
\hline \multirow[b]{2}{*}{ 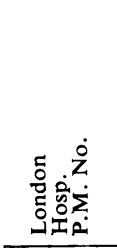 } & \multirow[b]{2}{*}{ 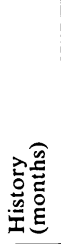 } & \multirow[b]{2}{*}{ 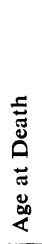 } & \multirow[b]{2}{*}{ 蔍 } & \multicolumn{4}{|c|}{$\begin{array}{c}\text { Histology of } \\
\text { Tumour }\end{array}$} & \multirow[b]{2}{*}{ 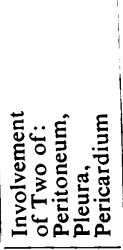 } & \multicolumn{6}{|c|}{ Metastases } & \multirow[b]{2}{*}{ 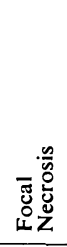 } & \multirow[b]{2}{*}{ 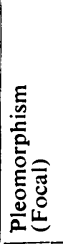 } \\
\hline & & & & 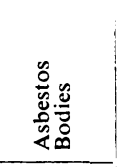 & 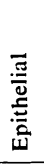 & 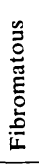 & 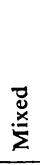 & & 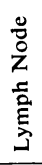 & ્ֻఝ & 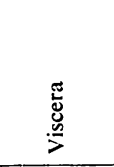 & 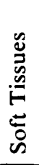 & 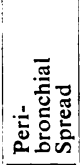 & 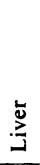 & & \\
\hline 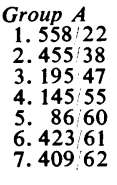 & $\begin{array}{l}1 \\
6 \\
2 \\
1 \\
1 \\
1 \\
8\end{array}$ & $\begin{array}{l}47 \\
37 \\
45 \\
77 \\
48 \\
45 \\
55\end{array}$ & $\begin{array}{c}\mathbf{M} \\
\mathbf{M} \\
\mathbf{F} \\
\mathbf{F} \\
\mathbf{M} \\
\mathbf{F} \\
\mathbf{M}\end{array}$ & $\begin{array}{c}+++(F) \\
+++(F) \\
+ \\
+(F) \\
+(F) \\
+(F)\end{array}$ & $\begin{array}{l}+ \\
\dot{t} \\
\dot{t} \\
+ \\
+ \\
+ \\
+\end{array}$ & $\begin{array}{l}- \\
- \\
- \\
- \\
+ \\
+ \\
+\end{array}$ & $\begin{array}{l}- \\
- \\
- \\
\bar{t} \\
+\end{array}$ & $\begin{array}{l}+ \\
+ \\
+ \\
+ \\
+ \\
+ \\
+\end{array}$ & $\begin{array}{l}+ \\
+ \\
+ \\
- \\
+ \\
+\end{array}$ & $\begin{array}{l}- \\
- \\
- \\
- \\
-\end{array}$ & $\begin{array}{c}- \\
\text { Pancreas } \\
- \\
- \\
- \\
\text { Adrenal } \\
-\end{array}$ & $\begin{array}{l}- \\
+ \\
- \\
+ \\
+ \\
-\end{array}$ & $\begin{array}{l}- \\
- \\
- \\
- \\
-\end{array}$ & $\begin{array}{l}- \\
- \\
- \\
- \\
+ \\
-\end{array}$ & $\begin{array}{l}+ \\
\pm \\
+ \\
- \\
-\end{array}$ & $\begin{array}{l}- \\
\overline{+} \\
- \\
- \\
\overline{+}\end{array}$ \\
\hline $\begin{array}{rr}\text { Group } & B \\
8.134 & 17 \\
9.517 & 17 \\
10.190 & 25 \\
11.119 & 26 \\
12.190 & 31 \\
13.491 & 35 \\
14.89 & 36 \\
15.171 & 42 \\
16.291 & 55 \\
17.247 & 62\end{array}$ & $\begin{array}{l}1 \frac{1}{2} \\
3 \\
1 \\
1 \\
-2 \\
2 \\
- \\
-1\end{array}$ & $\begin{array}{l}59 \\
23 \\
42 \\
61 \\
49 \\
61 \\
36 \\
69 \\
66 \\
74\end{array}$ & $\begin{array}{l}\mathbf{M} \\
\mathbf{F} \\
\mathbf{M} \\
\mathbf{M} \\
\mathbf{M} \\
\mathbf{M} \\
\mathbf{M} \\
\mathbf{M} \\
\mathbf{M} \\
\mathbf{M}\end{array}$ & $\begin{array}{c}? \\
? \\
? \\
? \\
? \\
? \\
\stackrel{+}{-} \\
\left.+\frac{+}{F}\right) \\
-\end{array}$ & $\begin{array}{l} \pm \\
- \\
+ \\
+ \\
+ \\
- \\
- \\
-\end{array}$ & $\begin{array}{l}\overline{+} \\
\pm \\
- \\
- \\
- \\
+ \\
- \\
-\end{array}$ & $\begin{array}{l}- \\
\overline{+} \\
\overline{+} \\
+ \\
- \\
+ \\
+ \\
+\end{array}$ & $\begin{array}{l}+ \\
+ \\
+ \\
+ \\
+ \\
+ \\
- \\
- \\
-\end{array}$ & $\begin{array}{l} \pm \\
- \\
+ \\
- \\
- \\
- \\
- \\
-\end{array}$ & $\begin{array}{l}- \\
+ \\
+ \\
+ \\
- \\
- \\
- \\
-\end{array}$ & $\begin{array}{c}\text { Adrenal } \\
\text { Pancreas } \\
- \\
- \\
- \\
- \\
- \\
- \\
-\end{array}$ & $\begin{array}{l}- \\
+ \\
+ \\
+ \\
- \\
- \\
- \\
+ \\
+\end{array}$ & $\begin{array}{c}- \\
\overline{+} \\
+ \\
+ \\
\overline{-} \\
\overline{+} \\
\overline{-} \\
-\end{array}$ & $\begin{array}{l}- \\
\overline{-} \\
- \\
\overline{+} \\
\overline{-} \\
- \\
-\end{array}$ & $\begin{array}{l}- \\
\overline{-} \\
+ \\
- \\
\overline{-} \\
+ \\
\overline{-}\end{array}$ & $\begin{array}{l}- \\
\overline{-} \\
- \\
-* \\
\overline{-} \\
\overline{+} \\
\overline{+}\end{array}$ \\
\hline
\end{tabular}

* Intrabronchial spread here queries diagnosis. $\quad \mathrm{F}=$ Fibrosis of lung.

morphism or scanty visceral metastases, but in which the majority of the features were classically those described and expected for mesotheliomata (probable cases).

Table I lists the salient pathological features of these pleural cases.

Of the 21 rejected cases, 16 had lung tissue available. Of these, one case showed an asbestos body. This case was an unusual sarcoma, involving lung, stomach, and pleura, and was thought to be a neurofibrosarcoma.

In Group A (seven cases) the age range was 37 to 77 years, and asbestos bodies were found in the lung in six cases. Only case 2 was known to have had asbestosis during life, with a long history of industrial exposure. Four of the remaining cases showed peribronchial and interstitial fibrosis in addition to asbestos bodies, and probably are cases of asbestosis. In case 7, despite demonstration of asbestos bodies during necropsy and subsequent close questioning of relatives, no history of industrial exposure was obtained.

In several of the cases, only very small numbers of bodies were found, and a random sample of lung tissue might easily have shown no bodies. In case 6 , bodies were looked for in fluid from fresh tissue and in multiple blocks of lung, but none was found.

All seven of these group A cases had tumour plaques in the peritoneum in addition to the main pleural lesion. Five of the seven showed metastases within the lymph nodes, usually hilar, mediastinal, or supraclavicular, and two cases showed metastases in the axillary nodes.

Invasion of soft tissue, defined as a macroscopic lump under the skin of the chest wall and confirmed histologically, was found in two cases.

Case 2 showed one focus of tumour in the pancreas, and case 6 one focus of tumour in an adrenal. Each of these organs was surrounded by peritoneal tumour.

In case 6 , the omentum was replaced by tumour and was adherent to the lower border of the liver, in which several tumour nodules were situated. All of these visceral lesions suggested origin by direct extension of tumour from outside.

The age distribution of group B (10 cases) is similar to that of group A, apart from case 9, a woman of 23 years. Men predominate in this group, and peritoneal tumour was present in $60 \%$. Lymph node metastases were less common (20\%), and visceral tumours, probably due to direct extension, were present in a few cases.

Case 9 was considered doubtful because of the age of the patient and because the tumour was entirely fibromatous in type, without typical cytology. However, the spread of tumour was within serous cavities, and bony and pancreatic metastases were in contact with serosal tumour so that direct invasion was likely. The tumour was extensive in the pre-vertebral fascia and entirely encased the right lung. No epithelial elements were 


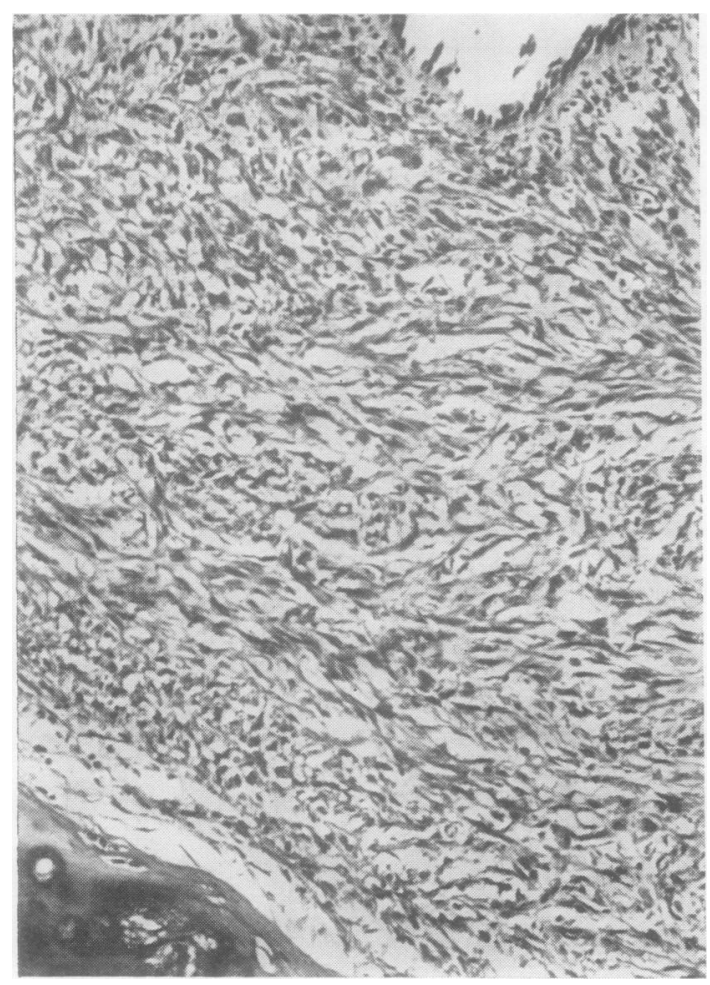

FIG. 10. Case 12. Fibromatous tumour between bronchia! mucosa (above) and cartilage (below). This renders the diagnosis of mesothelioma doubtful. Tubular epithelial elements were present in the main mass of tumour in the pleura. Haematoxylin and eosin, $\times 150$.

found, so that while one cannot firmly exclude fibrosarcoma of extrapleural tissue with secondary extension to involve the pleura, it seems likely to be a primary tumour of the pleura.

In two cases (10 and 12), in addition to extension of tumour into the interlobar septa (very common in mesothelioma) there was intrabronchial spread of tumour. This suggests that the tumours were primary carcinomata of the lung, but a study of the histology reveals several peculiar features. The cells within the bronchus in both cases were spindle-shaped (Fig. 10), despite pure epithelial type in the extrabronchial tissue in one case. The intrabronchial cells interdigitated with bronchial muscle, and in one case there was a polypoid projection into bronchial lumen. The pleural element of these two tumours was typical of other mesotheliomata, with epithelial or mixed histology. Some of the cells in intrabronchial tissue showed prominent red nucleoli, and I think these tumours were probably mesotheliomata. Primary carcinoma of the bronchus with this histology might be found, usually with squamous elements seen rather than adenocarcinoma. Mucin of epithelial type was not present in any of the tubules in these tumours. A primary fibrosarcoma or leiomyosarcoma of the bronchus was excluded because of the distinct tubular elements within the tumour.

Apart from the three doubtful cases, a further case (case 14) showed unusual features. The histology was fibromatous (uniformly) with no epithelial elements. The morbid anatomy was of a rounded massive tumour $(16 \mathrm{~cm}$. in diameter) with additional diffuse spread in both pleural cavities of sheets of white tumour. The blocks may have been taken from the large mass of tumour, but there was no evidence of any specific pleural origin in the slides, nor did the cells show the typical cytology of pleural tumour.

The other cases in group B were, in general, similar to those in group $\mathrm{A}$ and are probably mesotheliomata. Some cases with bronchial tumour are probably mesotheliomata, but primary carcinoma of the lung, although highly unlikely, cannot be firmly excluded.

In cases where no epithelial element is seen, fibrosarcoma of the pleura cannot be excluded. The point is probably unnecessarily pedantic, but I feel that most fibromatous tumours of the pleura can be recognized as being pleural in origin because of the cytology. In a few cases without this cytology, no pleural origin can be suspected, and although some fibromatous malignant tumours originating in pleura may not show this cytology, they could be classified as pleural on morbid anatomical grounds.

Cases of asbestosis commonly show fibrous or hyaline pleural plaques, and diffuse pleural thickening may also be seen. These must be differentiated from mesotheliomata, the fibromatous type of tumour being very similar to the benign thickening. Figure 11 shows the histology of benign pleural thickening in asbestosis, in which the visceral and parietal pleural layers are thickened and fused. The tissue is cellular, shows prominent foci of lymphocytes and plasma cells, and is identical to collagenous areas found focally in some of the fibromatous tumours (Fig. 7). However, in the tumours, invasion of soft tissues and foci of plump spindle cells were always found (Fig. 13). Lymph node metastases were rare in fibromatous tumours.

The peritoneal group of tumours was similarly reviewed: 55 tumours were studied and 17 accepted as certain or probable mesotheliomata. 


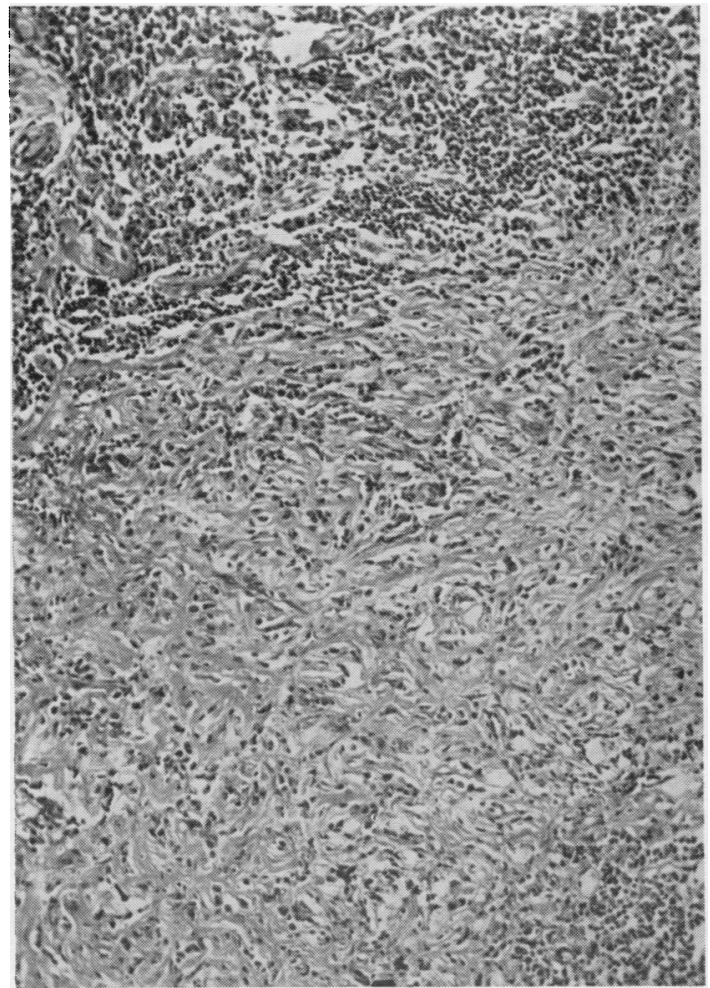

FIG. 11. Gross pleural thickening from a case of asbestosis thought to be benign (not in series). Photograph shows loosely arranged collagen with inflammatory cells aggregated at top and bottom. Compare with Fig. 7. Haematoxylin and eosin, $\times 110$.

The most difficult differential diagnosis was papillary cystadenocarcinoma of the ovary. As this is a common tumour, any case with the ovary enlarged by tumour, or with psammoma bodies or cilia present in the tumour on histological examination, was rejected from the series. Other tumours rejected were regarded as primary carcinoma of the stomach, pancreas, kidney, or adrenals.

Thirteen cases were classified as certain peritoneal mesotheliomata (group C) and four as probable (group D). Table II lists the main features.

In group C 11 cases had lung blocks available and in seven of these asbestos bodies were found $(63 \%)$. The morbid anatomy of the peritoneal tumours was largely comparable with that of the pleural lesions, but solid sheets of tumour were less common than multiple discrete or confluent nodules. Lymph node metastases were less com- mon, as were direct extensions into the viscera. Pure fibromatous tumours were not found.

In group $\mathrm{D}$, four cases were classified as probably mesothelial. In these either the cytology was not typical of the group or foci of pleomorphism were found. Areas of necrosis were quite common. Two cases had lung available for study, and asbestos bodies were seen in one case $(50 \%)$.

The absence of lymph node or liver metastases in a diffuse peritoneal neoplasm is very much against a primary tumour of the stomach, gut, or pancreas. Primary ovarian carcinoma remains the sole differential diagnosis, and the points against such a diagnosis have already been given. In some of these, tumour had spread across the surface of one or both ovaries, but in no case was the ovary enlarged nor was tumour found within the ovarian cortex or medulla.

Several of the peritoneal group had been included in a previous report (Keal, 1960). Four of

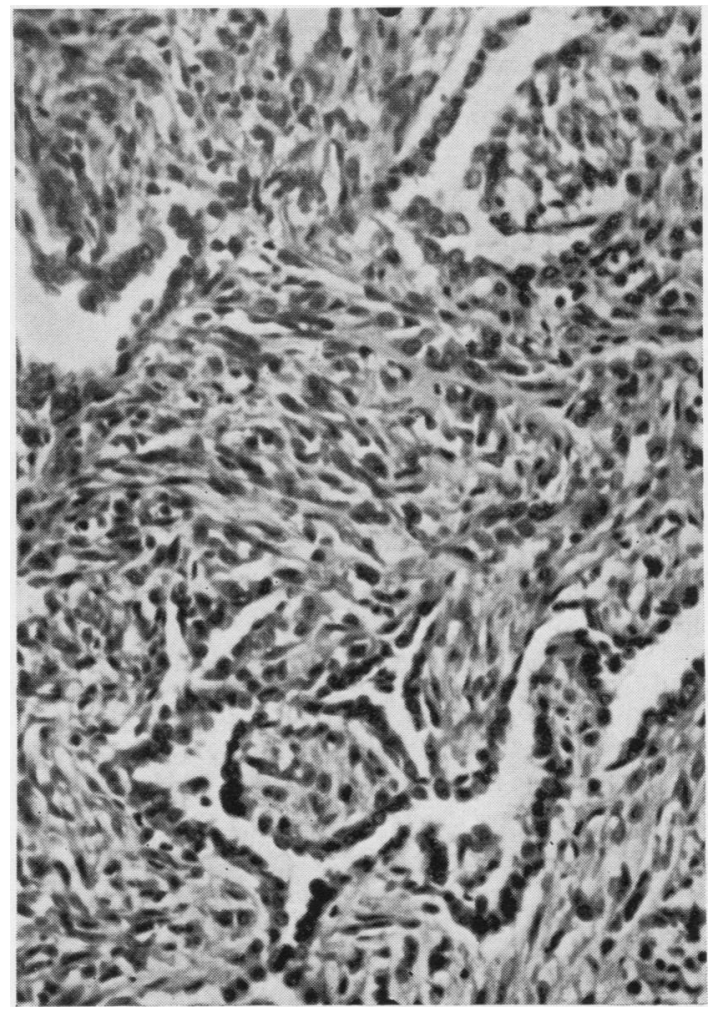

FIG. 12. Case 16. Fibromatous tumour abutting directly on epithelial type tubules. There is no transition between the two types, and the appearances are similar to those seen in malignant synovioma. Haematoxylin and eosin, $\times 150$. 
TABLE II

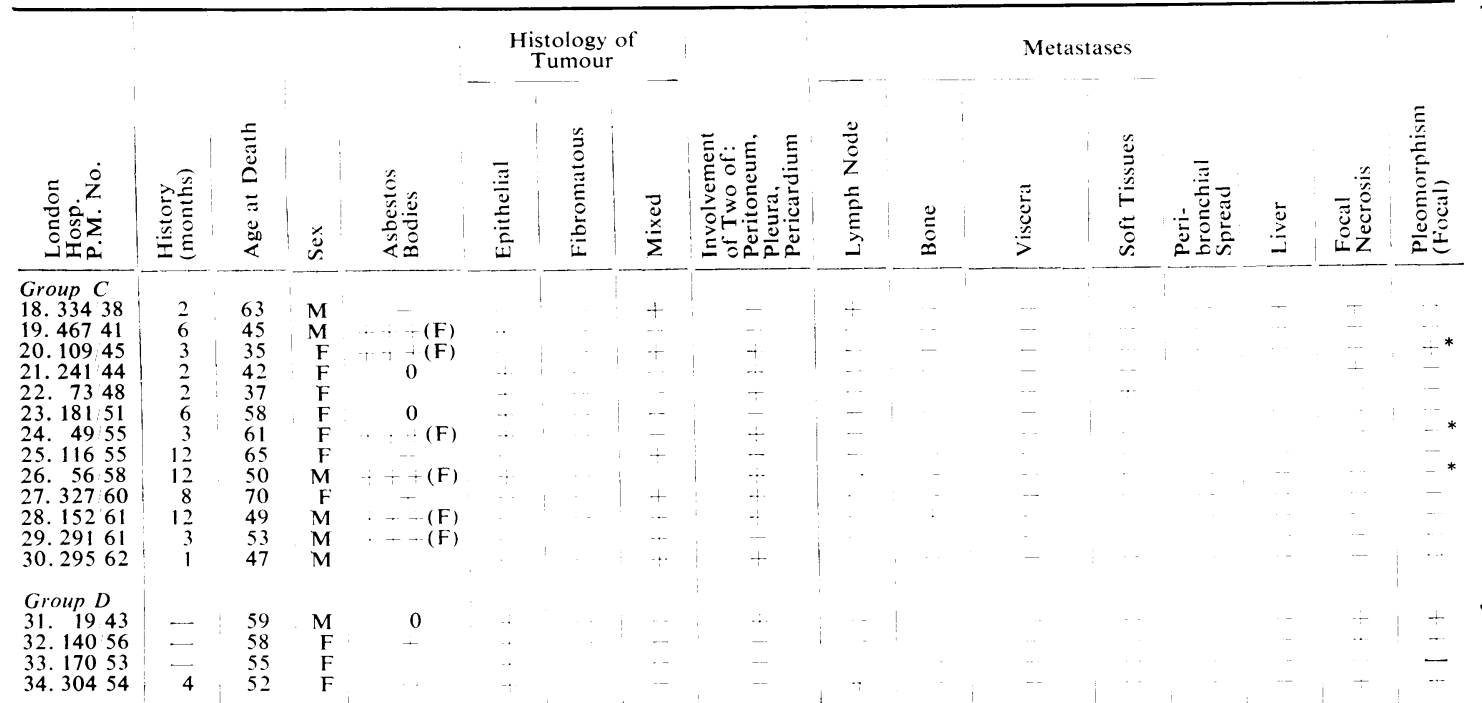

* Cases included in a previous report (Keal, 1950); Present series Case 2) (Keal's Case 9); Present series Case 24 (Keal's Case 3); Presen Series Case 26 (Keal's Case 24). F=Fibrosis of lung.

Keal's cases had had a necropsy examination, and I have classified three of these as peritoneal mesotheliomata.

Of the 37 peritoneal tumours rejected as mesotheliomata, 11 had lung tissue available, and in none of these were asbestos bodies seen.

\section{DISCUSSION}

The tumours here recorded are in accord with those in the literature (Godwin, 1957; Winslow and Taylor, 1960). There were no cases regarded as arising in the pericardium, although this was commonly involved by tumour which also involved the pleura or peritoneum.

Histologically, the mixed type, with epithelial and fibromatous elements, was most easily distinguished (Campbell, 1950), although occasionally the fibroblasts of young granulation tissue gave rise to difficulty in recognition and might easily be confused with the fibromatous element of a tumour. If the pattern of indistinct fasciculation, the relative paucity of blood vessels, and the cytology of the plump cells with prominent nucleoli were noted, then the difficulty was usually resolved. Foci of inflammatory cells were occasionally prominent within the tumours, usually lymphocytes and plasma cells, but diffuse inflammatory infiltrate was not seen.

When the fibromatous element abutted upon epithelial areas, the similarity of the cells was obvious (Fig. 12). Epithelial type tumours resembied adenocarcinomata, but the loose arrangement of the tubules, the regularity of the cells, the absence of epithelial mucin (P.A.S. stain). the infrequency of mitoses, and the cytology of the cells all suggested the possibility of mesothelioma. I think it is possible to be reasonably certain of mesothelioma when only a small piece of tissue is available (biopsy). The most difficult differential diagnosis is inflammatory pleural thickening, and when small pieces of tissue are all that is available, then the differential diagnosis may be impossible.

Collagenous, acellular areas may be found in each. In the cellular areas, the cells in inflam- 은 matory thickening are usually less plump than $\frac{D}{0}$ those in a tumour, but unless invasion of muscle or vessels is seen, this can still be a difficult $N$ distinction. The epithelial type of reaction in in- $\mathrm{N}$ flammatory lesions is usually restricted closely to the mesothelial surface, but tubules with papillae and folds are occasionally found.

Foci of inflammatory cells are prominent in benign (inflammatory) pleural thickening, but are $\Phi$ usually restricted to the deeper layers of the? pleura. Inflammatory cells in mesothelioma are $\frac{0}{0}$ only a feature when fibrin is present on the sur- $\overrightarrow{\mathbb{D}}$

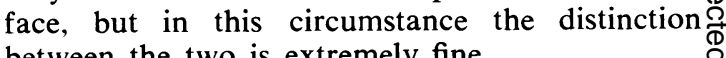
between the two is extremely fine.

This differentiation reaches its most difficult point in cases of asbestosis, where fibrous pleuralo 


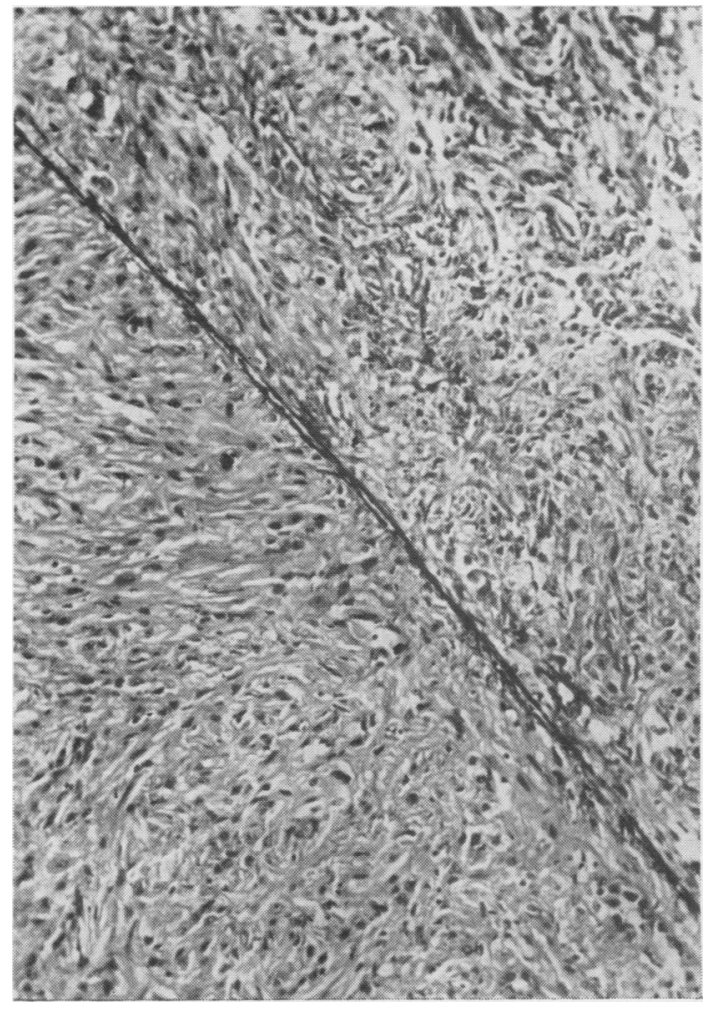

FIG. 13. Case 6. The intact elastic membrane of the visceral pleura runs obliquely across the field with fibromatous tumour on either side of it. Lung is above and to the right, and the tumour here has greatly thickened the normal thin layer of connective tissuc between elastic membrane and alveoli. Most pleural mesotheliomata are restricted to the depth shown here. Occasionally the most superficial pulmonary alveoli are invaded. The plump spindle-shaped cells below and to the left of the elastic membrane are found in all fibromatous mesotheliomata, although often only present in foci between less cellular collagenous areas. Compare with Figs. 7 and 11. Wigert's elastic tissue stain, counterstained with Van Gieson, $\times 120$.

thickening may cover a lung (Fig. 11). In the series presented here, the presence of metastases in lymph nodes was of crucial assistance in this distinction, but in all the necropsy cases, where multiple pieces of tissue were available for study, cellular foci with plump spindle cells were also found (Fig. 13), although sometimes these were infrequent.

Wagner, Munday, and Harington (1962) have suggested that metachromatic staining within a tumour (demonstrated by Hale's technique), and removable by exposure to hyaluronidase, is strong evidence in favour of mesothelioma. This, of course, is only applicable when stains for epithelial mucin are negative (P.A.S. or Southgate's mucicarmine). They suggest that the substance responsible for the metachromasia is hyaluronic acid, produced by the mesothelial cells, and a feature of mesotheliomata.

Hyaluronic acid is soluble in water (and in formol saline), and as most of the tissues of this study were formol fixed, this reaction was not found in my cases. In four cases, metachromatic staining was shown with thionine, the metachromatic material being situated within intracytoplasmic vacuoles (Fig. 5), the stains for epithelial mucin showing no reaction in these areas.

While this reaction probably is important in the recognition of mesotheliomata, caution must be exercised in the interpretation of metachromasia. A florid, mucoid, stromal reaction elicited by invasive carcinoma or by inflammation of the pleura may also exhibit similar metachromasia, and I feel that the material must be intracellular to be of significance from the point of view of mesothelioma. Harington, Wagner, and Smith (1963) have suggested that quantitative biochemical estimation of hyaluronic acid in pleural or peritoneal fluid may give diagnostic results, the levels being higher in cases of mesothelioma than in inflammatory or neoplastic lesions involving serosal surfaces.

Wagner (1960) first suggested an association between mesotheliomata and exposure to asbestos, and this study confirms this association. As a control group, the cases rejected from the series were used, and the results show a clear significant difference in incidence (Table III).

In an attempt to assess the incidence of asbestos bodies in necropsy tissues at this Institute, the lungs of 50 consecutive necropsies were examined for them, and none was found. (Cases of tumour within the chest were excluded.) The incidence in 50 cases of carcinoma of the lung studied post

T A B LE II I

\begin{tabular}{c|c|c|c|c}
\hline Group & $\begin{array}{c}\text { Lungs } \\
\text { Available }\end{array}$ & $\begin{array}{c}\text { Asbestos } \\
\text { Bodies or } \\
\text { Fibres }\end{array}$ & $\begin{array}{c}\text { Fibrosis } \\
\text { of } \\
\text { Lung }\end{array}$ & $\begin{array}{c}\text { Cases with } \\
\text { Asbestos Bodies } \\
\text { or Fibres (\%) }\end{array}$ \\
\hline A & 7 & 6 & 5 & 85 \\
B & 10 & 1 & 2 & 10 \\
C & 11 & 7 & 6 & 63 \\
D & 2 & 1 & 0 & 50 \\
E & 16 & 1 & 0 & $6 \cdot 5$ \\
F & 11 & 0 & 0 & 0 \\
H & 50 & 3 & 0 & 6 \\
\hline
\end{tabular}

Group A-certain pleural mesotheliomata. Group B-probable pleural mesotheliomata. Group C-certain peritoneal mesothelicmata. Group D-probable peritoneal mesotheliomata. Group E-rejected from pleural series. Group F-rejected from peritoneal series. Group $\mathrm{G}-$ consecutive necropsy cases of carcinoma of lung. Group $\mathrm{H}$-consecutive necropsy cases excluding tumours in chest. 
mortem was $6 \%$. Asbestos bodies were found in lung tissue and occasionally within hilar lymph nodes. They were never found in the pleura, within the tumour, or in any other viscus. Several foci in tumours with granules of brown pigment were examined for asbestos fibres after exposure to sulphuric acid (Gloyne, 1932), but none was seen.

While many of the cases were known to have had asbestosis before death, the majority were not, and asbestos bodies were an unexpected finding on histological examination. Several cases gave no history of exposure to asbestos dust, and some of these had very few bodies in the lungs (case 9 had one asbestos body; case 3 had two bodies), and it is possible that a temporary, perhaps trivial, exposure to asbestos dust had occurred, not necessarily related to industrial contact. It is of interest that the association with asbestos bodies was not restricted to any histological type, and the mixed or fibrous types were included in the association. No evidence as to how asbestos bodies affect the pleura and peritoneum was found. Asbestos bodies are common in sub-pleural parenchyma, but none was found within the abdominal viscera. It is possible that asbestos bodies and fibres might be fragmented and destroyed in these areas, but in the cases in which brown bodies were found within the neoplasms, these appeared to be banal haemosiderin granules.

Mesotheliomata of the pleura have been produced after direct implantation of asbestos dust into the pleural cavities of rats (Wagner, 1962), but the relevance of this to human pathology is not clear.

This has in no sense been a clinical study, but the short histories of these patients from the time of development of symptoms to death is a striking feature (Tables I and II). It can also be seen that the cases have occurred over a number of years at this Institute, and there appears to have been no decrease in recent years. An additional study of patients who have had surgical biopsies of tumours which appear to be mesotheliomata is at present in the course of preparation, and it is hoped to publish this shortly.

\section{SUMMARY}

A study of the pathology of 34 cases of primary tumours (mesotheliomata) of the pleura and peritoneum shows these to be distinct and recognizable neoplasms which can be distinguished from primary carcinomata of the lung or other viscera.

The association of these tumours with asbestos bodies in lung tissue is confirmed. Many of the cases gave no history of industrial exposure, and it is possible that temporary or relatively trivial exposure may have occurred.

Once symptoms from the tumours have arisen. the prognosis appears to be measured in months rather than years.

My thanks are due to Professor I. Doniach and to Dr. J. C. Wagner for encouragement in the preparation of this work.

The photographs were taken by Mr. J. King. to whom my thanks are due. as also to Mrs. J. Bamford for the secretarial work, done with the assistance of an M.R.C. grant.

\section{REFERENCES}

Campbell, W. N. (1950). Pleural mesothelioma. Amer. J. Path., 26, 473.

Enticknap, J. B., and Smither, W. J., (1964). Peritoneal tumours in asbestosis. Brit. J. Industr. Med., 21, 20

Gloyne, S. R. (1932). The asbestos body. Lancet, 1, 1351

Godwin, M. C. (1957). Diffuse mesotheliomas with comment on their relation to localized fibrous mesotheliomas. Cancer, 10, 298.

Harington, J. S., Wagner, J. C., and Smith, Marianne (1963). The detection of hyaluronic acid in pleural fluids of cases with diffuse pleural mesotheliomas. Brit. J. exp. Path., 44, 81.

Keal, E. E. (1960). Asbestosis and abdominal neoplasms. Lancet, 2, 1211

Klemperer, P., and Rabin, C. B. (1931). Primary neoplasms of the pleura. Arch. Path. 11, 385

McCaughey, W. T. E. (1958). Primary tumours of the pleura. J. Path. Bact., 76, 517.

Manguikian, B. and Prior, J. T. (1963). Mesotheliomas of the pleura. Arch. Path., 75, 236.

Smart, J., and Hinson, K. F. W. (1957). Pleural neoplasms. Brit. J. Tuberc., 51, 319.

Wagner, J. C. (1960). Proceedings of the Pneumoconiosis Conference, $\stackrel{\odot}{\times}$ Johannesburg, 1959, p. 373. Ed., A. J. Orenstein. Churchill. London.

(1962) Experimental production of mesothelial tumours of the pleura by implantation of dusts in laboratory animals. Nature (Lond.), 196, 180.

- Munday, D. E., and Harington, J. S. (1962). Histochemical demonstration of hyaluronic acid in pleural mesotheliomas. $J$. Path. Bact., 84, 73.

- Sleggs, C. A., and Marchand, P. (1960). Diffuse pleural mesothelioma and asbestos exposure in the north western Cape I Province, Brit. J. industr. Med., 17, 260.

Willis, R. A. (1960). Pathology of Tumours, 3rd ed. Butterworths, 三.

London.
Winslow, D. J., and Taylor, H. B. (1960). Malignant peritoneal $\mathcal{N}$ mesotheliomas. A clinicopathological analysis of 12 fatal cases. Cancer, 13, 127.

\section{ADDENDUM}

Since this paper was submitted for publication case 26 has been included in the series published by Enticknap and Smither (1964) as their case No.10.M. 